\title{
Pedagogia líquida: um caminho para a ciência da práxis
}

\author{
Claudia de Medeiros Lima ${ }^{\mathrm{I}, \text { II }}$
}

http://dx.doi.org/10.24109/2176-6681.rbep.99i253.3881

\footnotetext{
Instituto Federal do Ceará (IFCE). Fortaleza, Ceará, Brasil.E-mail:<clamed.lima@ hotmail.com>; <http://orcid org/0000-0002-9914-0585>.

II Mestre em Educação pela Universidade Federal de Sergipe (UFS). Sergipe, Aracaju, Brasil.

1 É importante registrar que a análise de documentos mais recentes, como a Resolução CNE/CP 2/2015, modificada pela Resolução CNE/ CP1/2017 que definem as Diretrizes Curriculares Nacionais para a formação inicial em nível superior, as quais abrangem o curso de Pedagogia, não registram alterações na essência da proposta de formação do pedagogo como prevista anteriormente na Resolução CNE/CP 1 de 2006.
} 
a superação da pedagogia como normatizadora e instrumentalizadora da atividade docente e sugere a apropriação dessa característica fluida como possibilidade de fortalecimento de sua identidade como ciência da práxis.

Palavras-chave: ciências da práxis; pedagogia; pedagogia líquida.

\section{Abstract \\ Liquid Pedagogy: a pathway to the science of praxis}

Pedagogy, whose identity is continually under discussion among educators, features once more; this time to reclaim its relevance twelve years after the implementation of the guidelines for this academic course. The starting point for this work is the systematization of some old discussions, some dating back from the course's creation, aiming to understand incongruities among the political-ideological field, the legislation and the practical-professional field, amidst the power struggles between education theorist and political legislators. The analysis of the ambiguity and flaccidity of pedagogy in its structural conditioning, therefore, will sit in two great axes seeking to substantiate the existence of a liquid pedagogy to the detriment of the sciences of praxis. The first axis is underpinned on the educational reform in Latin America and the Caribbean within the context of liquid modernity and the second one is underpinned on the relation between the interests of international organizations and the latest guidelines for the course. The investigation's theoretical-methodological perspective followed the critical line in the field of education and it is based chiefly on Mészáros (2008), Saviani (2013), Frigotto and Ciavatta (2003), Libâneo (2001; 2006; 2010), Pimenta (2006), Franco (2006; 2008), Kuenzer and Rodrigues (2007) and Silva (2006); as well as on Bauman's sociological concept of liquid modernity (2001; 2005). As for the material applied, primary and bibliographic sources were analyzed. The research signals towards a surpassing of pedagogy as standardizer and orchestrater of teaching and suggests the appropriation of this fluid characteristic as a fortifier of its identity as a science of praxis.

Keywords: Pedagogy; liquid pedagogy; the sciences of praxis.

\section{Introdução}

Ela é fluida, volátil. Pela sua natureza fugidia, penetra diferentes espaços e se molda à forma do invólucro que a retém, pelo menos momentaneamente, pois, se alguma brecha se abre, ela escorre e se 
esvai. Ela corre livre, desliza sob, sobre, por entre e fugazmente segue seu curso. Sua característica é a efemeridade, seu destino é a mudança. Mudar, transformar, ir sempre ao encontro do novo em constante devir. O alvo? Sempre foi o mesmo, por mais longo e largo o percurso que se tenha percorrido, é para ele, nele e por ele que ela brota, flui: o ser humano. Esse ser social, que se humaniza, aprende, evolui, educa-se com e através dos "outros".

A história nos conta que o pedagogo, na condição de escravo, já conduziu a criança para a aprendizagem, até posteriormente a pedagogia adquirir o status precário de ciência. Sua natureza epistemológica é confusa, polêmica, indefinida, mas resiste e se adapta, pois seu estado resvaladiço assim permite. A pedagogia, cuja identidade é contínuo objeto de discussão entre educadores, entra em cena mais uma vez como tema central deste artigo. Por que e a quem interessa manter a pedagogia alheia à pesquisa $\mathrm{e}$ à produção de conhecimento em educação?

É importante registrar que este trabalho surge como desdobramento da dissertação de mestrado em educação defendida na Universidade Federal de Sergipe e tem a pretensão de retomar a discussão sobre a relevância da pedagogia nos processos educativos após 12 anos da regulamentação das diretrizes do curso. Este estudo pretende sistematizar certas discussões antigas, algumas das quais datam da criação do curso, para compreender incongruências entre campo político-ideológico (pensamento/ planejamento), legislação (registro/regulamentação) e campo práticoprofissional (exercício/possibilidade), em meio às disputas de forças entre teóricos da educação e políticos legisladores.

Quando se discute sobre um objeto multifacetado, como a pedagogia, é importante elencar hierarquicamente as questões que o têm determinado e a conjuntura macrossocial em que tem se desenvolvido. A proposta de analisar a ambiguidade e a flacidez da pedagogia brasileira atual em seus condicionantes estruturais, portanto, partirá de dois grandes eixos que buscarão fundamentar a existência de uma pedagogia líquida em detrimento das ciências da práxis.

O primeiro eixo se sustenta na reforma educacional na América Latina e no Caribe dentro do contexto da modernidade líquida, subordinada à política econômica capitalista neoliberal globalizante. O segundo ergue seu alicerce sobre as últimas diretrizes do curso de pedagogia em consonância com os interesses dos organismos internacionais para a educação brasileira e com relações sociais e profissionais fugidias.

A perspectiva teórico-metodológica que fundamenta a pesquisa segue a linha crítica em educação, conforme citações seguintes. Quanto ao material utilizado, seguimos à análise das fontes primárias com a legislação educacional concernente à temática e à análise de fontes bibliográficas. Para discutir sobre o paradigma sócio-político-econômico, consideramos, essencialmente, obras de Bauman (2001; 2005), Mészáros (2008) e Zibechi (2017). Para as reformas educacionais e a pedagogia, tomamos Saviani (2013), Frigotto e Ciavatta (2003), Libâneo (2001; 2006; 
2010), Pimenta (2006), Franco (2006; 2008), Kuenzer e Rodrigues (2007) e Silva (2006).

Quanto à organização dos tópicos da escrita, ocupamo-nos com a forma e suas derivações etimológicas, protagonizadas pela pedagogia e pelos pedagogos. Portanto, forma, (re)forma, (de)forma e (trans)formação constituirão os pilares desse diálogo que se pode chamar pedagógico.

\section{A forma líquida moderna e a (re)forma ${ }^{2}$ da educação}

Uma epidemia de cegueira causada pelo excesso de luz advém sobre toda a sociedade. O ofuscante brilho e a claridade impedem que as pessoas enxerguem. No desespero do Ensaio sobre a cegueira (Saramago, 1996), as pessoas lutam entre si pela sobrevivência individual. A ficção ilustra a certeza da incerteza e a supremacia do indivíduo sobre o cidadão em meio ao caos social. Com base no confinamento humano, o autor nos apresenta a angústia, o medo e a ansiedade vivenciados pelos personagens da obra.

Mas o que é a modernidade líquida senão a era da cegueira ilustrada? Segundo Bauman (2001), a supremacia da razão moderna não trouxe a emancipação ansiada e reivindicada pela teoria crítica. A liquidez vem, assim, desconstruir padrões e dissolver valores universais, ao mesmo tempo que coloca sobre o próprio indivíduo a decisão e a responsabilidade de suas ações sociais. A falsa sensação de liberdade faz do homem refém de poderes indeterminados, outrora controlado pelo Estado, agora pela mão invisível do consumo globalizado.

O que de fato está em jogo no novo tipo de guerra na era da modernidade líquida: não a conquista de novo território, mas a destruição das muralhas que impediam o fluxo dos novos e fluidos poderes globais; expulsar da cabeça do inimigo, o desejo de formular suas próprias regras, abrindo assim o até então inacessível, defendido e protegido espaço para a operação dos outros ramos, não-militares, do poder.

(Bauman, 2001, p. 20).

O fluxo baumaniano nos apresenta o tempo e o espaço movediços, nos quais os sólidos são derretidos e submetidos à racionalidade técnica parametrizados pela economia. Nesse jogo de poder pulverizado entre as "forças transnacionais", o consumismo surge como nova forma de dominação instantânea, diminuindo a soberania do Estado. A nova reestratificação social originada caracteriza a separação entre estado e nação, tornando o primeiro um mero articulador político regulatório da economia das megaempresas (Bauman, 2001; 2005).

O crescimento vertiginoso dessa política econômica neoliberal nos países latino-americanos tem seu auge na década de 1990. Atendendo às recomendações formuladas no Consenso de Washington, que, segundo Frigotto e Ciavatta (2003), tinham em vista o potencial lucrativo do campo educacional, esses países deram início às suas (re)formas educacionais. Orquestradas pela Organização Mundial do Comércio (OMC) - cuja representação regional se deu pela Comissão Econômica para a América

\footnotetext{
2 (Re)forma, palavra cujo significado versa sobre a variação do modo pelo qual uma coisa existe ou se manifesta. Aqui, a reforma vista apenas como uma mudança na aparência, mas não na essência, delata a subordinação da educação às distintas facetas assumidas pelo capitalismo (Cunha, 1997).
} 
Latina e Caribe (Cepal) e pela Oficina Regional para a Educação na América Latina e no Caribe (Orealc) -, as reformas implementadas fundamentavam-se na capacitação profissional e na produção científico-tecnológica, em nome da democratização do acesso à educação básica, da eficiência e da equidade da educação.

As medidas adotadas a partir de então foram ao encontro da Teoria do Capital Humano, que, conforme Shiroma, Moraes e Evangelista (2011), atribuiu à educação a condição salvacionista da economia. Em defesa da competitividade, organismos multilaterais estabeleceram metas, traçaram planos, criaram um ideário para a elaboração das políticas educacionais da América Latina e do Caribe, das quais o Brasil foi signatário.

A década de 1990, então, amplamente debatida no cenário da educação como o período das grandes (re)formas educacionais, em que se destacam as ações de planejamento e financiamento, teve como princípio atender as necessidades básicas da educação para manter o emprego e dominar os códigos técnicos e tecnológicos modernos.

Zibechi (2017) informa que, logo após essa década neoliberal e a insurgência dos movimentos sociais, sucedeu-se o período progressista. Grande foi a expectativa sobre os estados governados por partidos de esquerda. Estes, no entanto, não negligenciaram os acordos internacionais e até fracassaram na proposta de diminuição da dependência histórica dos países latino-americanos e das desigualdades sociais agravadas pelo neoliberalismo. O arrefecimento da esquerda quando em posse do poder estatal a afastou dos ideais de base dos movimentos sociais.

O autor destaca ainda que, no caso brasileiro, apesar de o governo de esquerda que administrou o País por mais de uma década ter tirado milhões de pessoas da miséria, não conseguiu reduzir a desigualdade, tampouco o acúmulo de capital dos ricos. Aumentou o poder de consumo dos mais pobres, mas não realizou as reformas necessárias nas áreas básicas como educação, saúde e transporte. "Que hizo creer que era posible combatir la pobreza sin tocar los privilegios ni movilizar a los sectores populares" (Zibechi, 2017, p. 107).

Como transformar um país onde a desigualdade cresce progressivamente? Qual reforma em educação seria suficiente para democratizar a escola pública e de qualidade? Há como propor reformas em educação sem justiça social? Essas são questões retóricas, mas que já se sabe não coadunarem com as propostas ofertadas pela forma líquida moderna, representada pelo Estado mínimo e suas instituições precárias. Sob a lógica do capital, exige-se um povo "educado" conforme os rigores de qualidade, eficiência e competitividade. O alto padrão de educação determinado, contudo, revela-se inversamente proporcional à atenção e aos investimentos públicos na área.

Na dita era da informação, prevalece o discurso da necessidade de se educar. Na fala do político candidato ou do cidadão menos elucidado, a qualidade da educação passou a compor o ideário nacional como a solução para a transformação social, para a saída da pobreza. Nesse sentido, Frigotto e Ciavatta (2003) afirmam que as reformas vieram ajustar a educação escolar 
à nova divisão internacional do trabalho, cujos princípios de competência e empregabilidade fomentam a competição e o individualismo, em vez de promoverem o rompimento com a dependência histórica, intelectual e cultural dos países da América Latina e do Caribe.

Semelhantemente, o pânico estabelecido pela cegueira na obra de Saramago levou pessoas ao confinamento, à solidão. A aproximação da ficção com a cegueira esclarecida, causada pelo avanço do conhecimento científico e tecnológico, não pode ser mera coincidência. É premente a luta da humanidade contra a exclusão social na pós-modernidade, a qual, segundo a teoria baumaniana, tem revelado angústia, medo e isolamento social na disputa pela sobrevivência e por constituição de identidades.

$\mathrm{Na}$ afirmação de que as (re)formas educacionais propostas a partir da década de 1990 e as demais que as antecederam não superaram a lógica do capital, Saviani (2013) nos diz que estas seguiram o modelo da pedagogia tecnicista da década de 1970 em seus padrões de racionalidade, eficiência e produtividade, diferindo apenas na minimização do Estado e nas iniciativas do setor público em prol da esfera privada e das organizações não governamentais.

A supremacia neoliberal globalizada do consumo e sua política do descartável têm precarizado não somente o mundo do trabalho, mas as relações sociais e a construção do conhecimento. A efemeridade das coisas e a fragilidade das relações têm promovido ainda maior distanciamento entre classes sociais, fazendo com que boa parte da população mundial ainda não tenha acesso às condições básicas de cidadania. De qual reforma em educação e de qual pedagogia precisamos então?

Para Mészáros, qualquer reforma em educação que não esteja comprometida com a modificação da estrutura do capital não passa de mero ajuste para remediar os "piores efeitos da ordem reprodutiva capitalista estabelecida sem, contudo, eliminar os seus fundamentos causais antagônicos e profundamente enraizados" (Mészáros, 2008, p. 26, grifo do autor). Enquanto não invertermos a ordem da "coisificação dos homens e humanização das coisas", nenhuma reforma conseguirá promover emancipação e transformação social.

\section{A (re)forma da educação e a (de)forma ${ }^{3}$ da pedagogia}

A subordinação da educação ao sistema de produção capitalista não fez mais que conformar as relações sociais às regras gerais de reprodução, tornando impossível uma transformação social qualitativa. Essa análise de Mészáros, que por vezes soa pessimista, faz-nos refletir sobre a máxima freireana: "Se a educação sozinha não transforma a sociedade, sem ela tampouco a sociedade muda" (Freire, 2000, p. 67).

É preciso superar a tomada de decisão local pautada em parâmetros globalizados internacionais. Existem alguns movimentos recentes, a exemplo da pedagogia decolonial, ${ }^{4}$ que propõem alargar o diálogo

\footnotetext{
3 (De)forma, assim como a acepção do termo, faz alusão à mudança de forma, mas também sugere uma descaracterização que compromete o que poderia ser sua forma original, aqui sugerida como ciência da educação (Cunha, 1997).
}

4 Pedagogia decolonial: expressão utilizada para caracterizar o campo educativo como espaço de manifestação e resistência às heranças dos processos de colonização da América Latina e do Caribe, nas esferas de ser, saber e poder. Especialmente, na relação estabelecida entre modernidade/ciência e dominação por meio do padrão masculino, branco, europeu (Oliveira; Candau, 2010). 
educacional em suas bases política, epistemológica e ética, discutindo, sob a ótica do colonizado, as influências ocidentais sobre a América Latina.

Consonante com esse pensamento de resistência aos ditames internacionais, principalmente no que tange às propostas educacionais, é que este artigo propõe analisar a pedagogia líquida. Expressão essa apoiada na teoria baumaniana e cunhada por nós na dissertação de mestrado pela Universidade Federal de Sergipe, utilizada para discutir sobre a superfluidade da área de conhecimento que vacila entre a teoria e a prática, a investigação e a instrumentalização, a ciência e a experiência, a especialidade docência e a generalidade não docência, a saber, a pedagogia.

Muitos autores no País já escreveram acerca da construção histórica da identidade do curso de pedagogia. Apesar de este estudo utilizar o recorte a partir das influências das políticas educacionais que se iniciaram na década de 1990, não há como deixar de abordar a ambiguidade que permeia a trajetória do curso.

Foi o Decreto-Lei $\mathrm{n}^{\mathrm{o}}$ 1.190/1939 que criou oficialmente o curso de pedagogia a partir da organização da Faculdade Nacional de Filosofia. A imprecisão de formar bacharéis e licenciados segue as finalidades da faculdade e abrange todos os cursos ofertados. O esquema de formação $3+1$ (três anos de bacharelado mais um de didática) fora exigido para todas as licenciaturas: filosofia, matemática, física, química, história natural, geografia e história, ciências sociais, letras clássicas, letras neolatinas, letras anglo-germânicas (Brasil, 1939).

É certo que a lei também previa que, para ocupar os cargos técnicos em educação, seria exigida a habilitação em pedagogia, mas é possível observar entre suas finalidades uma formação mais ampla, voltada para a pesquisa. Nesse sentido, vale registrar as considerações que Franco (2006) faz sobre a criação do curso, a idealização de formar além de professores, também cientistas da educação, cuja proposta visava à superação do caráter utilitário dos institutos de educação em prol da alta cultura. Na prática, contudo, essa proposta se perdeu, talvez pelo fato de ter sido regulamentada durante a ditadura Vargas, conforme destaca a autora.

Diante das exigências de racionalidade técnica característica do período militar, estabelecem-se as habilitações do curso (magistério para disciplinas pedagógicas de $2^{\circ}$ grau; orientação educacional, supervisão e administração escolar). Nasce, portanto, a grande polêmica sobre a qual vai perdurar a natureza dicotômica da pedagogia até os dias atuais.

Imbuídos de romper com essa separação entre pensadores e executores da educação, educadores, a partir da redemocratização do País, intensificaram as discussões e lutaram pela legitimação do curso. Segundo Silva (2006), ${ }^{5}$ à época houve um processo conturbado entre sociedade civil e órgãos do governo, de modo que a questão da identidade da pedagogia foi arrefecida e, arrastando-se pela década de 1990, sob coordenação da Associação Nacional pela Formação dos Profissionais em Educação (Anfope), centrou-se na formação de educadores em geral, em busca da base comum nacional. 
É a Lei de Diretrizes e Bases (LDB), Lei no 9.394/1996, porém, que legitima a exclusão das habilitações específicas do curso e fortalece a premissa de formar, em nível superior, professores para as séries iniciais. Ela estabelece, no artigo 87, a década da educação, instituída no ano subsequente à sua publicação, e afirma no $\S 4^{\circ}$ : "somente serão admitidos professores habilitados em nível superior ou formados por treinamento em serviço" (Brasil, 1996). Em seguida, o Plano Nacional de Educação (PNE), sancionado pela Lei $\mathrm{n}^{\circ}$ 10.172/2001, que é responsável por elaborar as diretrizes e metas a serem executadas durante dez anos, obrigou os estados, o Distrito Federal e os municípios a produzirem seus respectivos planos decenais (Brasil, 2001).

Somente no ano de 2006, com a regulamentação das novas diretrizes do curso - Resolução CNE/CP n ${ }^{\circ} 1$-, circunscreve-se o perfil profissional do pedagogo na docência, que tacitamente a enclausura na formação para o ensino da educação infantil e das séries iniciais (Brasil. CNE, 2006).

Destacamos aqui dois pontos de análise sobre a (de)forma que torna a pedagogia corrediça e líquida: fundamentalmente, não se pode negar a conquista dos educadores representados pela Anfope. Naquele momento de acirrado debate em torno dos rumos da docência e do iminente risco de extinção do curso de pedagogia, conseguir estabelecer a docência como base da formação foi uma vitória. Tendo em vista, inclusive, que após a flexibilização da LDB, regulamenta-se o Decreto no $3.276 / 1999$, que instituiu o curso normal superior como ambiente específico para formação docente da educação infantil e dos anos iniciais do ensino fundamental (Brasil, 1999).

Essa disposição legal abriu uma disputa com a pedagogia e gerou preocupação com a qualidade da formação promovida nos novos cursos, que não necessariamente seriam ofertados por universidades (Silva, 2006; Brzezinski, 2011). Por isso, circunscrever a formação docente à pedagogia seria uma forma de preservar a qualidade nessa formação.

Dessa maneira, podemos considerar que, apesar da conquista da não extinção do curso de pedagogia, estávamos cedendo mais uma vez aos interesses dos órgãos do governo em atender as metas estabelecidas para a educação básica na Declaração Mundial sobre Educação para Todos. Qualificar professores seria uma das contribuições para melhorar os índices da educação básica. As diretrizes em 2006 legitimaram o curso, mas isso resolveu o problema? Parece-nos que não. A pedagogia resolveria o problema da fragilidade de formação dos professores da educação infantil e das séries iniciais, porém, sua questão identitária permaneceu indefinida. Reduzida à docência, retrocedeu na busca de seu status de ciência, produtora de conhecimento em educação.

Esse segundo ponto, que talvez tenha sido o argumento mais utilizado em defesa da docência como base formativa, previa a superação dos distanciamentos provocados pelas antigas habilitações e pela formação para o magistério. Dessa forma, aparentemente, a divisão entre bacharéis e licenciados se encerra. Já vimos, todavia, que essa questão histórica de afastamento entre teoria e prática na educação não era um problema exclusivo da pedagogia. 
Quando trazemos a locução "redução da pedagogia à docência", utilizamos com o mesmo valor semântico usado por Libâneo (2010), Pimenta (2006), Franco (2006) e Kuenzer e Rodrigues (2007), que não menosprezam a docência, mas antes a compreendem como uma das expressões da pedagogia. Em complemento a essa construção, defendemos que a redução à docência incidiu sobre a essência do curso de pedagogia, porque sua natureza se deformou, liquefez-se. Quando as diretrizes do curso a indicaram para a licenciatura, entretanto, abriram uma multiplicidade de atuação sem conseguir convencer de que maneira se daria tal formação, e acrescenta-se a isso a precariedade do exercício profissional.

Nesse sentido, Libâneo (2006) e Kuenzer e Rodrigues (2007) concordam que as diretrizes favoreceram uma indefinição profissional para o pedagogo. Lançamos aqui uma questão para reflexão: se todo pedagogo é professor por formação, não deveríamos lutar pelo fim da exigência do campo de trabalho por pedagogos técnicos? Não parece ter sentido, por exemplo, haver concursos específicos para gestores, coordenadores, supervisores ou orientadores educacionais nas instituições escolares públicas. Na prática, esses profissionais continuarão distantes da sala de aula, exclusivos às atividades de "pensar a educação".

Libâneo (2001) defende a necessidade de especialistas nas escolas. As desigualdades não estão na diferença entre trabalho docente e trabalho pedagógico, isso não é superar a divisão técnica do trabalho, segundo o autor. As desigualdades permanecerão sob outras circunstâncias. A questão destacada por ele é a sobrecarga de trabalho em virtude do acúmulo de funções na docência.

Não há como discordar da necessidade de profissionais dedicados exclusivamente às questões administrativas e pedagógicas, sob o risco de minimizar ou anular todo o trabalho escolar/acadêmico a ser desenvolvido. Esse ponto parece estar consolidado entre aqueles que defendem a docência como base da pedagogia e aqueles que a consideram como mais uma possibilidade dentro de um universo científico mais amplo. É sobre essa segunda possibilidade que prosseguiremos o diálogo.

\section{A pedagogia líquida e o caminho para a (trans)formação ${ }^{6}$ da ciência da práxis}

Chamamos de pedagogia líquida o campo de conhecimento que emerge após a Resolução CNE/CP n ${ }^{\circ}$ 1/2006 e que se apresenta instrumentalizado, cujo foco nas práticas de ensino e aprendizagem subestima seu potencial científico-epistemológico sobre os processos educativos. De caráter

6 Originalmente, o significado da palavra é "alteração no estado de um sistema". Aqui também utilizado para sugerir a liquidez como estado atual da pedagogia, que vai adquirindo novas formas abrindo outras possibilidade para mudança (Cunha, 1997). indefinido, aparentemente generalista, mas delineado na docência, percorre espaços escolares e não escolares com a fluidez que lhe é peculiar. Encaixando-se nos diferentes perfis e executando vários papéis profissionais, para os quais não estão preparados, os pedagogos enfrentam as incertezas da profissão, característica da modernidade líquida. "Estamos agora passando da fase 'sólida' da modernidade para a fase 'fluida'. E os 
'fluidos' são assim chamados porque não conseguem manter a forma por muito tempo [...]" (Bauman, 2005, p. 57).

Em torno de toda indefinição acerca da pedagogia no País, ao longo dos seus quase 80 anos, predomina o pensamento que desconsidera a latente capacidade de produzir conhecimento sobre a realidade educativa, que supera a prática social e se apresenta mais abrangente que um curso de graduação (Libâneo, 2010; Pimenta, 2006; Kuenzer; Rodrigues, 2007).

A pedagogia líquida dilui o campo de conhecimento, esvazia-o para entrar indefinida em diferentes esferas do magistério: infantil, anos iniciais do ensino fundamental, educação especial, indígena, profissional, de jovens e adultos. Perde o status de ciências, entretanto, ocupa os espaços da não docência, em tarefas técnico-administrativas, de supervisão, orientação e coordenação escolar ou mesmo fora dos ambientes de escola, em organizações não governamentais e empresas, adaptando-se, tomando formas no exercício da profissão.

As diretrizes do curso, que parecem preconizar uma identidade sólida docente, sofrem influência da liquidez pós-moderna, propondo possibilidades plurais de atuação profissional, sem, contudo, especificá-las. Isso fica evidente, principalmente, nos artigos $2^{\circ}$ e $4^{\circ}$ da Resolução CNE/CP $n^{\circ} 1$, quando mencionam:

\section{[...] destina-se à formação de professores para exercer funções de magistério na Educação Infantil e nos anos iniciais do Ensino Fundamental; nos cursos de Ensino Médio, na modalidade Normal; de Educação Profissional na área de serviços e apoio escolar e em outras áreas nas quais sejam previstos conhecimentos pedagógicos. (Brasil. CNE, 2006, art. $4^{\circ}$, grifo nosso).}

Nesse sentido, Kuenzer e Rodrigues (2007, p. 260) consideram que "[...] o que está em tudo não está em lugar nenhum, constituindo-se dessa forma uma aberração categorial: uma totalidade vazia." Em busca de atender às dissonantes propostas para as diretrizes do curso, definiu-se ampliar de forma excessiva o perfil profissional.

O resultado disso é a diminuição da presença desses profissionais nas instituições escolares. É o enfraquecimento da pedagogia como campo teórico-investigativo, como pontua Pimenta (2006). Essa redução da cientificidade e dos conhecimentos epistemológicos no processo de formação dos pedagogos coaduna com os interesses pragmáticos e imediatistas exigidos pela pós-modernidade, sob os ditames da política econômica do descartável, do consumismo, do transitório, da formação "fast food", rápida e prática, mas sem qualidade ou preocupação com os resultados em longo prazo.

Para Kuenzer e Rodrigues (2007), além de reduzir o campo da pedagogia, privilegia-se a prática em detrimento da teoria, ao invés de promover articulação entre ambas. As autoras entendem que existe uma perda na formação como resultado da demasiada valorização do conhecimento tácito, destituindo-a de sistematização teórica. Essa pedagogia instrumental proposta se resume em ações práticas transmitidas pelos trabalhadores 
mais experientes no próprio ambiente de trabalho, mas que não é suficiente porque o conhecimento é recriado no pensamento. "[...] O ato de conhecer não prescinde do trabalho intelectual, que é um movimento do pensamento que não se desenvolve espontaneamente, precisando ser aprendido" (Kuenzer, 2003 apud Kuenzer; Rodrigues, 2007, p. 270).

A pedagogia líquida apresenta-se na instabilidade estrutural pósmoderna, que provém das transformações sociais e produtivas, provocadas pela política econômica capitalista neoliberal. Em meio às crises de vínculo social e profissional estabelecidas, surgiu um perfil profissional capaz de atender às demandas do capital: diminuição e precarização de ambientes de trabalho; acúmulo de funções para o trabalhador; perfil multifacetado. Esse "novo" pedagogo agora é o mesmo professor que passa a ter responsabilidades que transcendem a sala de aula. É o profissional que atende às propostas da acumulação flexível e que parece fazer acreditar que o ambiente escolar depende única e exclusivamente do professor. Nesse sentido, Libâneo (2006, p. 7) acrescenta:

[...] todo docente é um pedagogo, mas nem todo pedagogo precisa ser docente, simplesmente porque docência não é a mesma coisa que pedagogia [...] A subsunção da pedagogia na docência leva a duas deduções: a) sendo a docência, e não a pedagogia, a base da organização do currículo de formação, exclui-se a formação do pedagogo especialista, já que não se faz mais a diferenciação entre as atribuições profissionais do especialista em educação e as do professor; b) a extensão do conceito de "atividades docentes" para atividades de gestão e pesquisa levou a agregar ao trabalho do professor mais duas atribuições: a de investigador lato e stricto sensu, e a de gestor.

Mas do que precisamos? Resgatar a já superada formação dicotômica que distanciava ainda mais docentes e técnicos da educação? Evidentemente que não. Faz-se necessário pensar na concepção da educação como enfrentamento crítico da estrutura do capital, uma educação que, segundo Mészáros, é desenvolvida em um processo de mudança consciente. A educação seria o órgão social indispensável para a transformação estrutural, que, diferentemente do ideal capitalista, não deve ser imperativa, mas a soma das consciências dos indivíduos sociais. "[...] Não se pode vencer uma força social poderosa pela ação fragmentada de indivíduos isolados [...]" (Mészáros, 2008, p. 86).

Há uma necessidade premente de contestação do determinismo neoliberal globalizante e do desenvolvimento de conscientização/ mobilização do sujeito social. No caso específico deste estudo, a pedagogia liquefeita confere aos pedagogos outras possibilidades de atuação, resultado menos de determinações do que de resistência, luta e construção de nova identidade profissional pelos próprios indivíduos em coletividade.

Esse delineamento realizado pelas diretrizes do curso se encaixou perfeitamente na definição de liquidez baumaniana, proporcionando ao próprio indivíduo experimentar uma pluralidade de identidades profissionais, sem, contudo, definir o seu caráter científico. Uma pedagogia líquida que se escorre epistemologicamente pelo caminho da docência pragmatista, tornando sem sentido sua existência. 
Na tentativa de reconstruir uma identidade sólida, discutiu-se por muito tempo sobre os dilemas do curso. Entre leis, decretos e regulamentos, procurou-se uma resposta para a complexa questão: para que servem a pedagogia e os pedagogos? Sobre a problemática, Libâneo (2010), Pimenta (2006) e Franco (2008) apontam para a necessidade de resgate do seu estatuto científico-pedagógico, desprendendo-a do modo instrumentalizador que há tempos está associado à concepção professor/instrutor.

\begin{abstract}
A crescente dissociação entre atividade educativa e o exercício pedagógico foi produzindo a não valorização científica da pedagogia que, abdicando de ser a ciência da educação, foi se contentando em ser apenas um instrumento de organização da instrução educativa. (Franco, 2008, p. 72).
\end{abstract}

A pedagogia líquida manifesta na atual relatividade espaço-temporal se propõe menos universalista, todavia, para além de estar entre uma coisa e outra ou em região fronteiriça, revela a necessidade de resgate do seu caráter científico-epistemológico. Em busca da superação dessa dicotomia histórica, Franco (2006, p. 105) considera:

Não podemos mais nos contentar com a formação restrita desse pedagogo. Não mais devemos nos colocar na dimensão exclusiva de: pedagogo especialista ou pedagogo cientista, ou pedagogo escolar, ou mesmo pedagogo docente. E preciso absorver a multidimensionalidade desta formação, mas é fundamental esforços na construção de uma nova profissionalidade pedagógica.

Essa nova profissionalidade pedagógica aventada pela autora coaduna também com a ideia de uma pedagogia líquida, cujas relações de trabalho frágeis e frouxas sugerem a emergência de outra formação e expressão profissional que se sustente em si mesma. A base científico-epistemológica resgata seu caráter investigativo e formativo como área que tem na educação seu objeto de estudo. Para Franco (2008), é preciso priorizá-la como ciência específica da educação, pois outras ciências não dão conta da complexidade e da superfluidade das manifestações educativas, podendo, inclusive, descaracterizá-las.

"[...] Organizar-se já é começar a ter olhos" (Saramago, 1996, p. 282). A expressão utilizada assinalou a solução para a cegueira coletiva da obra fictícia trazida no início deste diálogo. Enquanto as iniciativas permanecerem restritas à individualidade pessoal, não haverá transformação. No livro, uma personagem despertou e buscou pela organização coletiva das ações, com isso o autor chamou atenção para a necessidade do despertar do egoísmo tão característico do capitalismo. Como propor outra pedagogia com base em iniciativas isoladas?

Para Mészáros (2008), não há como propor mudanças paradigmáticas em educação sem desenvolver individualidade social e sem provocar mudanças no modelo político e econômico capitalista hegemônico, pois a educação é considerada agente determinado e, ao mesmo tempo, determinante das relações sociais de produção. Em Bauman (2005), percebemos que a liquidez presente nos sugere possibilidades de abertura 
de espaços e de ressignificação das relações sociais estabelecidas na disputa, na luta e na resistência.

Diante de tais considerações, sugerimos uma reflexão decolonial sobre o curso de pedagogia. Cônscios de uma concepção educacional para atender a realidade brasileira, que nos afastemos das (re)formas pensadas pelos organismos internacionais para favorecimento do individualismo, do lucro e da competição capitalistas, e, apropriados do processo histórico-cultural de dominação da América Latina, lutemos por uma educação comprometida com a transformação social.

A pedagogia líquida age como facilitadora para abertura de outra proposta formativa e funcional do sistema educacional. Uma pedagogia que forme cientistas da educação que promovam pesquisa e produção teórica com base na práxis educativa (Franco, 2008), mas que também se habilitem para o exercício técnico-profissional, conforme proposta de Pimenta (2006) e Libâneo (2006).

A práxis é o princípio sobre o qual a ciência pedagógica promoverá a teorização das questões educativas e proporá intervenções na prática docente para a promoção da emancipação. A práxis é dinâmica, é dialética, depende da reflexão sobre a ação e não se desenvolve unilateralmente. Dessa forma, Franco (2008) propõe à pedagogia uma metodologia própria que a afasta do caráter racional técnico e da função normatizadora docente que perdura até hoje.

A validação da ciência da práxis propõe a articulação entre docência e ensino, que depende menos da superação das habilitações específicas da pedagogia do que do resgate do estatuto de ciências; menos de iniciativas isoladas do que do fortalecimento de grupos que desejam o reconhecimento de uma ciência exclusiva para a educação; menos de um ideal de educação importado do que da libertação do pensamento colonizado pelos modelos "padrões"; e menos ainda dos ditames do capital do que das utopias que nos impelem para a transformação social.

\section{Algumas considerações}

As análises realizadas neste artigo ratificam a subordinação da educação brasileira aos ditames dos organismos internacionais. Transvestidos de reformas, cujo lema liberal oportuniza educação de qualidade para todos, têm mascarado a realidade de um modelo subserviente ao capitalismo neoliberal globalizado.

A dependência, que não se faz somente econômica e política, mas intelectual e científica, tem contribuído para o País permanecer no imaginário colonizado que ainda prepondera sobre a América Latina e o Caribe. Essa construção social também tem influenciado o modelo de pedagogia que temos.

A pedagogia líquida foi a expressão criada para buscar compreender a área de saber, que, delineada pela precariedade da pós-modernidade, tem se afastado cada vez mais do seu estatuto de ciências em prol da 
instrumentalização e normatização do fazer docente. Ora, não possuir uma ciência específica para produzir conhecimento em educação é o cenário ideal para importação de modelos educacionais prontos que nada dizem sobre nossa realidade.

As diretrizes do curso, portanto, já regulamentadas há 12 anos, não mudaram a realidade imprecisa da pedagogia, pelo contrário. A ideia de transformá-la em licenciatura, pelas mais nobres intenções de valorizar a formação docente para a educação básica, ocultou interesses de indivíduos a serviço do capital estrangeiro. O resultado é o que discutimos ao longo do trabalho, uma pedagogia que está em tudo e não está em nada ao mesmo tempo, como bem assinala Kuenzer e Rodrigues (2007), que se faz presente nos espaços escolares e não escolares, mas que não se faz produtora de saber em educação.

Tal qual o momento da criação do curso, a produção teórica em educação continua primordialmente em outras áreas. Não temos uma ciência exclusiva da educação. Desenvolvemos uma pedagogia que corroborou a mecanização da docência por meio da priorização de métodos e técnicas, em uma visão pragmatista da educação.

Não dá para pensar em uma educação transformadora com uma atuação pedagógica embasada na racionalidade técnica. Para superarmos o poder hegemônico e o domínio do capital, precisamos modificar a política das estruturas e processos educacionais. A pedagogia como uma força estruturante da educação não pode permanecer, então, com essa fragilidade em sua identidade.

A pedagogia líquida atende a interesses macroeconômicos internacionais e tem ajudado a construir uma educação não conscientizadora, que enfraquece os indivíduos sociais e fragiliza a coletividade. Essa liquidez pode favorecer a descontinuidade de um projeto de ciências da práxis e, consequentemente, impedir o avanço teórico-prático em educação.

Diante do tom pessimista, todavia, apresentamos a superfluidade da pedagogia como uma possibilidade de surgimento de outra expressão que venha a fortalecer sua identidade científica. Na liquidez retratada, talvez, seja mais fácil resgatar esse estatuto epistemológico. Faz-se, contudo, imprescindível uma coletividade de pensamentos decolonizados para a continuidade da busca dessa ciência da práxis.

\section{Referências}

BAUMAN, Z. Identidade: entrevista a Benedetto Vecchi. Tradução Carlos Alberto Medeiros. Rio de Janeiro: Zahar, 2005.

BAUMAN, Z. Modernidade líquida. Tradução Plínio Dentzien. Rio de Janeiro: Zahar, 2001. 
BRASIL. Decreto no 3.276, de 6 de dezembro de 1999. Dispõe sobre a formação em nível superior de professores para atuar na educação básica, e dá outras providências. Diário Oficial da União, Brasília, DF, 7 dez. 1999. Seção 1, p. 4.

BRASIL. Decreto-Lei no 1.190, de 4 de abril de 1939. Dá organização à Faculdade Nacional de Filosofia. Diário Oficial da União, Rio de Janeiro, 6 abr. 1939. Seção 1, p. 7929.

BRASIL. Lei no 10.172, de 9 de janeiro de 2001. Aprova o Plano Nacional de Educação e dá outras providências. Diário Oficial da União, Brasília, DF, 10 jan. 2001. Seção 1, p. 1.

BRASIL. Lei no 9.394, de 20 de dezembro de 1996. Estabelece as diretrizes e bases da educação nacional. Diário Oficial da União, Brasília, DF, 23 dez. 1996. Seção 1, p. 27833.

BRASIL. Conselho Nacional de Educação (CNE). Resolução CNE/CP n ${ }^{\circ}$ 1, de 15 de maio de 2006. Institui diretrizes curriculares nacionais para o curso de graduação em pedagogia, licenciatura. Diário Oficial da União, Brasília, DF, 16 maio 2006. Seção 1, p. 11.

BRZEZINSKI, I. Pedagogo: delineando identidade(s). Revista UFG, Goiânia, v. 13, n. 10, p. 20-22, jul. 2011.

CUNHA, A. G. Dicionário etimológico Nova Fronteira da língua portuguesa. Rio de Janeiro: Nova Fronteira, 1997.

FRANCO, M. A. S. Para um currículo de formação de pedagogos. In: PIMENTA, S. G. (Org.). Pedagogia e pedagogos: caminhos e perspectivas. 2. ed. São Paulo: Cortez, 2006. p. 99-125.

FRANCO, M. A. S. Pedagogia como ciência da educação. 2. ed. São Paulo: Cortez, 2008.

FREIRE, P. Pedagogia da indignação: cartas pedagógicas e outros escritos. São Paulo: Ed. da UNESP, 2000.

FRIGOTTO, G.; CIAVATTA, M. Educação básica no Brasil na década de 1990: subordinação ativa e consentida à lógica do mercado. Educação \& Sociedade, Campinas, v. 24, n. 82, p. 93-130, abr. 2003.

KUENZER, A. Z.; RODRIGUES, M. F. Curso de pedagogia ou Normal Superior? Revista Brasileira de Política e Administração da Educação, Goiânia, v. 23, n. 2, p. 253-275, maio/ago. 2007.

LIBÂNEO, J. C. Diretrizes curriculares da pedagogia: imprecisões teóricas e concepção estreita da formação profissional de educadores. Educação \& Sociedade, Campinas, v. 27, n. 96, p. 843-876, out. 2006. 
LIBÂNEO, J. C. Pedagogia e pedagogos, para quê? 12. ed. São Paulo:

Cortez, 2010.

LIBÂNEO, J. C. Pedagogia e pedagogos: inquietações e buscas. Educar em Revista, Curitiba, v. 17, n. 17, p. 153-173, 2001.

MÉSZÁROS, I. A educação para além do capital. Tradução Isa Tavares.

2. ed. São Paulo: Boitempo, 2008.

OLIVEIRA, L. F.; CANDAU, V. M. F. Pedagogia decolonial e educação antirracista e intercultural no Brasil. Educação em Revista, Belo Horizonte, v. 26, n. 1, p. 15-40, abr. 2010.

PIMENTA, S. (Org.). Pedagogia e pedagogos: caminhos e perspectivas. 2. ed. São Paulo: Cortez, 2006.

SARAMAGO, J. Ensaio sobre a cegueira. São Paulo: Cia. das Letras, 1996.

SAVIANI, D. História das ideias pedagógicas no Brasil. 4. ed. Campinas: Autores Associados, 2013.

SHIROMA, E. O.; MORAES, M. C. M.; EVANGELISTA, O. Política educacional. Rio de Janeiro: Lamparina, 2011.

SILVA, C. S. B. Curso de pedagogia no Brasil: história e identidade. 3. ed. Campinas: Autores Associados, 2006.

ZIBECHI, R. Los movimientos em la crisis del progresismo. In: WALSH, C. Pedagogías decoloniales: práticas insurgentes de resistir, (re)existir y (re)vivir. Quito: Abyayala, 2017. p. 105-116. (Serie Pensamiento Decolonial).

Recebido em 7 de maio de 2018.

Aprovado em 15 de agosto de 2018. 